\title{
FAKTOR- FAKTOR YANG BERHUBUNGAN DENGAN STATUS DESA ODF (OPEN DEFECATION FREE) DI WILAYAH KERJA PUSKESMAS BULELENG III KABUPATEN BULELENG TAHUN 2021
}

\author{
Made Arini ${ }^{1}$, I Ketut Aryana ${ }^{2}$, Anysiah Elly Yulianti ${ }^{3}$
}

\begin{abstract}
The status of ODF Village (Open Defecation Free) shows a nation whose people have behaved clean and healthy lives, especially all chapters in latrines that are decent and safe. The purpose of this research is to find out Faktot - factors related to the status of ODF village in the working area of Buleleng Iii Health Center buleleng regency in 2021. This type of research is quantitative with descriptive analytical research design that aims with the approach used in this study is cross sectional.. The total number of families sampled was 12,923 families and samples in this study as many as 99 respondents with simple random sampling techniques Instruments used is a questionnaire. The data was analyzed univariate and bivariate with chi square test. The results showed a relationship between education level $(\rho=0.042)$, knowledge level $(\rho=$ 0.035), income level $(\rho=0.035)$, and support of village officials and community leaders $(\rho=0.035)$ with odf village status in the working area of Buleleng Ii Health Center buleleng regency in 2021. This research advice is submitted to the relevant parties to participate in realizing the status of ODF village by providing counseling and environmental health interventions.
\end{abstract}

Keywords : Factors that affect, Latrines, ODF

\section{PENDAHULUAN}

Permasalahan kesehatan Beberapa penelitian menyebutkan masyarakat di Indonesia masih ditandai dengan tingginya angka kesakitan dan kematian penyakit yang berbasis lingkungan. Kondisi tersebut masih kita jumpai di daerah pedesaan, penyakit yang penularannya berkaitan dengan air dan lingkungan terutama penyakit diare masih endemis dan masih merupakan masalah kesehatan. tentang hubungan dan pengaruh sanitasi buruk oleh karakteristik dan perilaku penjamu terhadap terjadinya penyakit infeksi. Diperkirakan $88 \%$ (penelitian lain 90\%) kematian akibat diare di dunia disebabkan oleh kualitas air, sanitasi dan higiene yang buruk. Dalam suatu studi disebutkan bahwa meningkatnya sistem pembuangan tinja efektif mencegah 
kejadian diare. Sebuah penelitian di Indonesia menyebutkan bahwa keluarga yang buang air besar sembarangan (BABS) dan tidak mempunyai jamban berrisiko 1,32 kali anaknya terkena diare akut dan 1,43 kali terjadi kematian pada anak usia dibawah lima tahun dan sarana jamban berrisiko 17,25 kali terkena diare pada bayi dan balita. .

Pada profil Dinas Kesehatan Kabupaten Buleleng Jumlah perkiraan kasus penderita diare di Kabupaten Buleleng pada tahun 2019 berjumlah 17.836 kasus atau $10 \%$ dari jumlah penderita. Dari 17.647 kasus yang diperkirakan, sebanyak 8.768 kasus diare yangtercatat dan mendapat pelayanan sesuai standar atau sebesar 49,2\%,sedangkan untuk kasus diare pada balita cakupan mencapai $30,3 \%$.

Sejalan dengan itu pemerintah melalui Permenkes Nomor 3 Tahun 2014 tentang Sanitasi Total Berbasis Masyarakat (STBM) melaksanakan program unggulan dalam mengatasi penyakit diare berbasis kewilayahan yaitu program Stop Buang Air Besar Sembarangan (SBS) atau Open Defecation Free (ODF) di seluruh provinsi ${ }^{2}$. Water-borne diseases merupakan penyakit yang ditularkan ke manusia akibat adanya cemaran baik berupa mikroorganisme ataupun zat pada air. Kerugian akibat water-borne disease terjadi pada manusia dan juga berdampak pada lingkungan tempat manusia tinggal. ${ }^{3}$.

Menurut Sholikhah Kurangnya penyuluhan tentang Open Defecation Free (ODF) juga berdampak pada perilaku warga ${ }^{4}$.

Upaya untuk mengurangi perilaku masyarakat yang $\mathrm{BAB}$ dengan menyusun rencana kerja tentang kesehatan lingkungan dan pembinaan peran serta masyarakat yang belum memiliki jamban dengan meningkatkan pengetahuan masyarakat di bidang kesehatan lingkungan khususnya tentang pentingnya kepemilikan dan pemanfaatan jamban

Tujuan dari penelitian ini Diketahuinya Faktor-faktor yang berhubungan dengan Status desa ODF di Wilayah Kerja Puskesmas Buleleng III Kabupaten Buleleng Tahun 2021 


\section{METODE PENELITIAN}

Jenis penelitian ini adalah kuantitatif dengan desain penelitian deskriptif analitik yang bertujuan untuk mengetahui gambaran serta hubungan antar variabel dependen dan independen. Pendekatan yang digunakan pada penelitian ini adalah cross sectional, yaitu penelitian yang pengukuran atau pengamatannya dilakukan secara simultan pada satu saat ${ }^{5}$. Populasi dalam penelitian ini adalah seluruh penduduk di wilayah kerja Puskesmas Buleleng III Kabupaten Buleleng jumlah 12.932 KK. Setelah dilakukan perhitungan dengan rumus Jadi besar sampel dalam penelitian ini yaitu $99 \mathrm{KK}$. Teknik pengambilan sampel menggunakan teknik simple random sampling.

\section{HASIL DAN PEMBAHASAN}

\section{Tingkat Pengetahuan}

Tabel 1

Distribusi Responden Berdasarkan Tingkat Pengetahuan

Di Wilayah Puskesmas Buleleng III Tahun 2021

\begin{tabular}{ccc}
\hline $\begin{array}{c}\text { Tingkat } \\
\text { Pengetahuan }\end{array}$ & Jumlah & $\%$ \\
\hline $\begin{array}{c}\text { KURANG } \\
\text { BAIK }\end{array}$ & 9 & 9,1 \\
BAIK & 90 & 90,9 \\
\hline Total & 99 & 100 \\
\hline
\end{tabular}

Dari hasil penelitian mengenai tingkat pendidikan responden terhadap Status Desa ODF diperoleh dari hasil wawancara kepada responden dalam kategori baik sebanyak 90 orang $(90,9 \%)$, dan dalam kategori kurang baik sebanyak 9 orang $(9,1 \%)$.

\section{a. Tingkat Pendapatan}

Tabel 2

Distribusi Responden Berdasarkan

Tingkat Pendapatan

Di Wilayah Puskesmas Buleleng III Tahun 2021

\begin{tabular}{ccc}
\hline $\begin{array}{c}\text { Tingkat } \\
\text { Pendapatan }\end{array}$ & Jumlah & $\%$ \\
\hline$<1.500 .000$ & 9 & 9,1 \\
$>1.500 .000$ & 90 & 90,9 \\
\hline Total & 99 & 100 \\
\hline
\end{tabular}

Dari hasil penelitian mengenai tingkat pendapatan responden terhadap Status Desa ODF 
diperoleh hasil wawancara kepada responden yaitu jumlah responden dengan pendapatan $\quad<1.500 .000$ sebanyak 9 orang $(9,1 \%)$ dan pendapatan $>1.500 .000$ sebanyak 90 orang $(90,9 \%)$

\section{c. Dukungan Aparat Desa dan Tokoh Masyarakat}

Tabel 3

Distribusi Responden Berdasarkan Tanggapan terhadap Dukungan Aparat Desa dan Tokoh Masyarakat

Di Wilayah Puskesmas Buleleng III Tahun 2021

\begin{tabular}{ccc}
\hline $\begin{array}{c}\text { Dukungan } \\
\text { Aparat Desa } \\
\text { dan Tokoh } \\
\text { Masyarakat }\end{array}$ & Jumlah & $\%$ \\
\hline $\begin{array}{c}\text { KURANG } \\
\text { BAIK }\end{array}$ & 9 & 9,1 \\
BAIK & 90 & 90,9 \\
\hline Total & 99 & 100 \\
\hline
\end{tabular}

Dari hasil penelitian mengenai dukungan aparat desa dan tokoh masyarakat terhadap Status Desa
ODF diperoleh hasil wawancara kepada responden yaitu jumlah responden dengan status belum ODF sebanyak 9 orang $(9,1 \%)$ dan responden dengan status ODF sebanyak 90 orang $(90,9 \%)$.

\section{Status Desa ODF}

Tabel 4

Distribusi Responden Berdasarkan Status Desa ODF Di Wilayah Puskesmas Buleleng III

Tahun 2021

\begin{tabular}{ccc}
\hline $\begin{array}{c}\text { Status Desa } \\
\text { ODF }\end{array}$ & Jumlah & $\%$ \\
\hline Belum ODF & 55 & 55,6 \\
ODF & 44 & 44,4 \\
\hline Total & 99 & 100 \\
\hline
\end{tabular}

Dari wawancara yang dilakukan diperoleh hasil yaitu responden dengan status ODF sebanyak 55 orang $(55,6 \%)$ dan belum ODF sebanyak 44 orang $(44,4 \%)$ 


\section{Hubungan Tingkat Pendidikan Responden Dengan Status Desa ODF}

Tabel 5

Hubungan Tingkat Pendidikan Responden terhadap Status Desa ODF di Wilayah Kerja Puskesmas Buleleng III Kabupaten Buleleng tahun 2021

\begin{tabular}{|c|c|c|c|c|c|c|c|}
\hline \multirow{3}{*}{ Tingkat Pendidikan } & \multicolumn{6}{|c|}{ Status Desa ODF } & \multirow{3}{*}{ Nilai $p$} \\
\hline & \multicolumn{2}{|c|}{ Belum ODF } & \multicolumn{2}{|c|}{ ODF } & \multirow[b]{2}{*}{$\mathrm{n}$} & \multirow[b]{2}{*}{$\%$} & \\
\hline & $\mathrm{n}$ & $\%$ & $\mathrm{n}$ & $\%$ & & & \\
\hline $\begin{array}{c}1 \\
\text { (Tidak Sekolah, } \\
\text { Tamat SD dan SMP } \\
\text { sederajat) }\end{array}$ & 25 & 55,6 & 20 & 44,4 & 45 & 100 & 0,042 \\
\hline $\begin{array}{c}2 \\
\text { ( SMA dan Perguruan } \\
\text { Tinggi) }\end{array}$ & 19 & 35,2 & 35 & 64,8 & 54 & 100 & \\
\hline Jumlah & 44 & 44,4 & 55 & 55,6 & 99 & 100 & \\
\hline
\end{tabular}

Pada Tabel 13 menunjukkan bahwa dari 54 responden dengan pendidikan kategori 2 terdapat 19 orang $(35,2 \%)$ yang belum ODF dan Sebanyak 35 orang $(64,8 \%)$ yang ODF. Dan Dari 45 responden dengan pendidikan kategori 1 terrdapat 25 orang $(55,6 \%)$ yang belum ODF dan sebanyak 20 orang $(44,4 \%)$ yang ODF.

Pendidikan kesehatan adalah suatu upaya atau kegiatan untuk menciptakan perilaku masyarakat yang kondusif untuk kesehatan, artinya, pendidikan kesehatan berupaya agar masyarakat atau mencegah hal-hal yang merugikan mereka. Tujuan akhir dari pendidikan kesehatan adalah agar masyarakat dapat mempraktikkan hidup sehat bagi dirinya sendiri dan bagi masyarakat ${ }^{6}$.

Hal ini sejalan dengan penelitian yang membahas tentang analisis faktor yang berhubungan dengan pemanfaatan jamban, yang menyatakan bahwa menyadari atau mengetahui bagaimana cara memelihara kesehatan mereka, bagaimana menghindari pendidikan 
tidak berhubungan dengan perilaku Buang Air Besar Sembarangan ${ }^{7}$.

Berdasarkan hasil penelitian bahwa pendidikan tinggi tetapi penerapan di dalam kehidupan sehari-hari yang kurang sehingga pendidikan ini tertutupi oleh perilaku yang tidak baik dan di dasari oleh kebiasaan yang sering dilakukan dalam kehidupan masyarakat desa. Namun perilaku masyarakat dalam memanfaatkan jamban tidak hanya berasal dari pendidikan formal saja, melainkan dari pengalaman pribadi waktu berpergian ke luar lingkungan tempat tinggalnya.

Menurut Green (2000) pendidikan merupakan faktor yang berpengaruh dalam membentuk pengetahuan, sikap, persepsi, kepercayaan dan penilaian seseorang terhadap kesehatan, sehingga dapat disimpulkan bahwa semakin tinggi pendidikan seseorang makan semakin tinggi pula kesadarannya untuk tetap menjaga kebersihan dan lingkungannya ${ }^{8}$. 


\section{Hubungan Tingkat Pengetahuan responden dengan Status Desa ODF}

Tabel 6

Hubungan Tingkat Pengetahuan Responden terhadap Status Desa ODF di Wilayah Kerja Puskesmas Buleleng III Kabupaten Buleleng Tahun 2021

\begin{tabular}{|c|c|c|c|c|c|c|c|}
\hline \multirow{3}{*}{$\begin{array}{c}\text { Tingkat } \\
\text { Pengetahuan }\end{array}$} & \multicolumn{4}{|c|}{ Status Desa ODF } & \multirow[b]{3}{*}{$\mathrm{n}$} & \multirow[b]{3}{*}{$\%$} & \multirow{3}{*}{ Nilai $p$} \\
\hline & \multicolumn{2}{|c|}{ Belum ODF } & \multicolumn{2}{|c|}{ ODF } & & & \\
\hline & $\mathrm{n}$ & $\%$ & $\mathrm{n}$ & $\%$ & & & \\
\hline \multicolumn{8}{|l|}{ KURANG } \\
\hline BAIK & 7 & 77,8 & 2 & 22,2 & 9 & 100 & 0,035 \\
\hline BAIK & 37 & 41,1 & 53 & 58,9 & 90 & 100 & \\
\hline Jumlah & 44 & 44,44 & 55 & 55,56 & 99 & 100 & \\
\hline
\end{tabular}

Pada tabel 6 menunjukkan bahwa dari 90 responden dengan tingkat pengetahuan baik terdapat sebanyak 37 orang $(41,1 \%)$ yang belum ODF dan 53 orang $(58,9 \%)$ yang ODF. Dan dari 9 responden dengan tingkat pendidikan kurang baik terdapat 7 orang $(77,8 \%)$ yang belum ODF dan sebanyak 2 orang $(22,2 \%)$ yang ODF. Dari hasil uji statistik menggunakan Chi Square dengan $\alpha=0,05$, didapatkan nilai $p$ $=0,035$, karena nilai $p<0,05$ maka Ha diterima dan $\mathrm{H}_{0}$ ditolak, artinya ada hubungan antara tingkat pengetahuan responden dengan status Desa ODF di wilayah kerja Puskesmas Buleleng III Kabupaten Buleleng Tahun 2021.
Pengetahuan dipengaruhi oleh faktor pendidikan formal pengetahuan sangat erat hubungannya dengan pendidikan, dimana diharapkan bahwa dengan pendidikan yang tinggi maka orang tersebut akan semakin luas pula pengetahuannya. Pengetahuan buruk terhadap BABS membuat seseorang terbiasa melakukan BABS tanpa mengetahui dampak dari perilaku tersebut 9 . Adanya hubungan pengetahuan dengan perilaku buang air besar sembarangan. Berdarkan hasil penelitian pada data persentase responden kasus ditunjukkan dengan responden yang berpengetahuan buruk berperilaku BABS di semak-semak, 
di kebun dan diparit dan menumpang. Sedangkan responden yang memiliki pengetahuan kategori baik berperilaku BAB tetapi masih ada juga masyarakat yang berpengetahuan baik yang masih BABS dimana memiliki WC tetapi dialirkan sungai, dan tidak bisanya buang air besar dijamban ${ }^{10}$.
Berdasarkan data - data diatas, peneliti berasumsi bahwa tingkat pengetahuan yang rendah akan membuat responden malas meluangkan waktu untuk mencari tahu status desa ODF atau responden sudah tahu akan pentingnya

\section{Hubungan Tingkat Pendapatan Responden Dengan Status Desa ODF}

Tabel 7

Hubungan Tingkat Pendapatan Responden terhadap Status Desa ODF di Wilayah Kerja Puskesmas Buleleng III Kabupaten Buleleng tahun 2021

\begin{tabular}{|c|c|c|c|c|c|c|c|}
\hline \multirow{3}{*}{$\begin{array}{c}\text { Tingkat } \\
\text { Pendapatan }\end{array}$} & \multicolumn{4}{|c|}{ Status Desa ODF } & \multirow[b]{3}{*}{$\mathrm{n}$} & \multirow[b]{3}{*}{$\%$} & \multirow{3}{*}{ Nilai $p$} \\
\hline & \multicolumn{2}{|c|}{ Belum ODF } & \multicolumn{2}{|c|}{$\mathrm{ODF}$} & & & \\
\hline & $\mathrm{n}$ & $\%$ & $\mathrm{n}$ & $\%$ & & & \\
\hline$<1.500 .000$ & 7 & 77,8 & 2 & 22,2 & 9 & 100 & \multirow{3}{*}{0,035} \\
\hline$>1.500 .000$ & 37 & 41,1 & 53 & 58,9 & 90 & 100 & \\
\hline Jumlah & 44 & 44,44 & 55 & 55,56 & 99 & 100 & \\
\hline
\end{tabular}

Pada tabel 7 menujukkan bahwa dari 90 responden dengan tingkat pendapatan $>1.500 .000$ terdapat sebanyak 37 orang $(41,1 \%)$ yang belum ODF dan 53 orang $(58,9 \%)$ yang ODF. Dan dari 9 responden dengan tingkat pendapatan $<1.500 .000$ terdapat sebanyak 7 orang $(77,8 \%)$ yang belum ODF dan sebanyak 2 orang $(22,2)$ yang ODF. Dari hasil uji statistik menggunakan Chi Square dengan $\alpha=0,05$, didapatkan nilai $p$ $=0,035$, karena nilai $p<0,05$ maka Ha diterima dan $\mathrm{H}_{0}$ ditolak, artinya ada hubungan antara tingkat pendapatan responden dengan status Desa ODF di wilayah kerja 
Puskesmas Buleleng III Kabupaten

Buleleng Tahun 2021.

Pendapatan dan sosial ekonomi yang baik dapat menciptakan sanitasi lingkungan yang baik karena kebutuhan terpenuhi dengan adanya materi yang cukup, sehingga tercipta kesehatan keluarga yang diharapkan. Dinegara berkembang, sebagai akibat tingkat sosial ekonomi yang rendah, sanitasi lingkungan yang belum diperhatikan masih merupakan masalah utama sehingga munculnya berbagai jenis penyakit menular tidak dapat dihindari dan pada akhirnya akan menjadi penghalang bagi tercapainya kemajuan bidang soaial dan ekonomi. Kondisi ini umumnya terjadi pada masyarakat pedesaan dan daerah kumuh perkotaan karena tingkat pendapatan yang rendah ${ }^{11}$.

Dari data yang diperoleh, tingkat pendapatan yang cukup seseorang dapat memenuhi semua kebutuhan baik primer maupun sekunder, namun dengan tingkat pendapatan yang kurang, seseorang akan berusaha memprioritaskan kebutuhan primer terlebih dahulu, hal ini sesuai juga dengan penelitian dilakukan yang memberikan hasil ditemukan adanya hubungan signifikan antara tingkat pendapatan dengan status desa ODF ${ }^{12}$.

\section{Hubungan Dukungan Aparat Desa dan Tokoh Masyarakat dengan Status Desa ODF}

Tabel 8

Hubungan Dukungan Aparat Desa dan Tokoh Masyarakat dengan Status Desa ODF di Wilayah Kerja Puskesmas Buleleng III Kabupaten Buleleng tahun 2021

\begin{tabular}{|c|c|c|c|c|c|c|c|}
\hline \multirow{3}{*}{$\begin{array}{c}\text { Dukungan } \\
\text { Aparat Desa dan } \\
\text { Tokoh } \\
\text { Masyarakat }\end{array}$} & \multicolumn{5}{|c|}{ Status Desa ODF } & & \multirow{3}{*}{ Nilai $p$} \\
\hline & \multicolumn{2}{|c|}{ Belum ODF } & \multicolumn{2}{|c|}{ ODF } & \multirow[b]{2}{*}{$\mathrm{n}$} & \multirow[b]{2}{*}{$\%$} & \\
\hline & $\mathrm{n}$ & $\%$ & $\mathrm{n}$ & $\%$ & & & \\
\hline KURANG & 7 & 77,8 & 2 & 22,2 & 9 & 100 & \\
\hline BAIK & & & & & & & 0,035 \\
\hline BAIK & 37 & 41,1 & 53 & 58,9 & 90 & 100 & \\
\hline Jumlah & 44 & 44,44 & 55 & 55,56 & 99 & 100 & \\
\hline
\end{tabular}

Pada tabel 8 menujukkan bahwa tentang Dukungan Aparat Desa dan dari 90 responden menanggapi Tokoh Masyarakat yang baik 
terdapat sebanyak 37 orang $(41,1 \%)$ yang belum ODF dan 53 orang $(58,9 \%)$ yang ODF. Dan dari 9 responden menanggapi tentang Dukungan Aparat Desa dan Tokoh Masyarakat yang kurang baik terdapat sebanyak 7 orang $(77,8 \%)$ yang belum ODF dan sebanyak 2 orang $(22,2 \%)$ yang ODF. Dari hasil uji statistik menggunakan Chi Square dengan $\alpha=0,05$, diperoleh nilai $p=0,035$, karena nilai $p<0,05$ maka $\mathrm{Ha}$ diterima dan $\mathrm{H}_{0}$ ditolak, artinya ada hubungan Dukungan Aparat Desa dan Tokoh Masyarakat dengan status Desa ODF di wilayah kerja Puskesmas Buleleng III Kabupaten Buleleng Tahun 2021.

Jenis dukungan dapat dilihat dari 2 aspek, yaitu dukungan berupa pemberian penyuluhan atau informasi mengenai jamban sehat, dan selanjutnya dukungan berupa bantuan jamban di lingkungan tempat tinggal responden. Apabila pemberian bantuan diatas tidak diimbangi dengan dukungan berupa penyuluhan atau pemberian informasi status desa ODF dan himbauan untuk tidak buang air besar sembarangan (BABS) khususnya bagi responden yang memiliki anak balita. Akibatnya perubahan perilaku masyarakat untuk menggunakan jamban sebagai sarana BAB tidak berlangsung lama ${ }^{13}$.

\section{SIMPULAN DAN SARAN}

Adapun simpulan dan saran dalam penelitian ini adalah :

Ada hubungan faktor tingkat pendidikan, pengetahuan,pendapatan, dan dukungan apara desa serta tokoh masyarakat dengan status desa ODF di wilayah kerja Puskesmas Buleleng III Kabupaten Buleleng tahun 2021 serta adapun saran bagi puskesmas, dinas kesehatan, aparat desa beserta tokoh masyarakat dan masyarakat yaitu lebih meningkatkan kerjasama lintas program dan lintas sektor, lebih meningkatkan anggaran untuk kegiatan pemicuan, membuat perarem / aturan mengenai larangan bebas buang air besar sembarangan, dan disertai dengan sanksi bila ada yang melanggar dan membuat jamban sesuai dengan penghasilan. 


\section{DAFTAR PUSTAKA}

1. Widowati. Hubungan

Karakteristik Pemilik rumah

dengan perilaku buang air

besar sembarangan di wilayah

kerja Puskesmas Sambung

Macan II. (Universitas

Muhammadiyah Surakarta, 2015).

2. Kementerian Kesehatan RI.

Peraturan Menteri Kesehatan

Republik Indonesia Nomor 3

Tahun 2014 tentang Sanitasi

Total Berbasis Masyarakat. (2014).

3. Triyono, A. Faktor-Faktor yang Berhubungan dengan

Perilaku Buang Air Besar

Masyarakat Nelayan di

Kampung Garapan Desa

Tanjung Pasir Kabupaten

Tangerang Provinsi Banten.

Forum Ilm. 11, (2014).

4. Hidayah, N. Upaya

Pencegahan Dampak Negatif

Open Defecation Free (ODF)

Di Dusun Sengon Desa Trasan

Kecamatan Bandongan

Kabupaten Magelang. $J$.

Kreat. Pengabdi. Kpd. Masy.

3, 508-514 (2020).

5. Sugiyono. Metode Penelitian
Kuantitatif Kualitatif dan

$R \& D$. (Alfabeta, 2012).

6. Notoatmodjo, S. Promosi

Kesehatan Teori dan Aplikasi.

(Rineka Cipta, 2010).

7. Anggoro, F. Analisis faktor

yang berhubungan dengan

pemanfaatan jamban di

Kawasan Perkebunan Kopi. e-

jurnal Pustaka Kesehat. 3,

(2015).

8. Notoatmodjo. Promosi

Kesehatan dan Perilaku

Kesehatan. (Rineka Cipta, 2007).

9. Wawan, A. Teori \&

Pengukuran Sikap dan

Perilaku Manusia. (Nuha

Medika, 2010).

10. Qudsiyah, A. Faktor-faktor

yang berhubungan dengan

tingginya angka open

defecation (OD) di Kabupaten

Jember (Studi di Desa Sumber

Kalong Kecamatan Kalisat).

e-journal Pustaka Kesehat. 3, (2015).

11. Chandra. Pengantar

Kesehatan Lingkungan. (EGC, 2007).

12. Pelneti, D. Faktor-Faktor yang

Berhubungan dengan 
Kepemilikan dan Keadaan

Jamban Keluarga di Desa

Percut Kecamatan Percut Sei

Tuan Kabupaten Deli

Serdang. (Universitas Negeri

Yogyakarta, 2013).

13. Erlinawati, P. Pengaruh

Perilaku Keluarga terhadap

Pengunaan Jamban. $J$.

Kesehat. Masy. 3, 230-234

(2009). 